\title{
Rescue Robots at the Collapse of the Municipal Archive of Cologne City: a Field Report
}

\author{
Thorsten Linder \\ Fraunhofer IAIS \\ Schloss Birlinghoven \\ Sankt Augustin, NRW, Germany \\ thorsten.linder@iais.fraunhofer.de \\ Peter Molitor \\ Fraunhofer IAIS \\ Schloss Birlinghoven \\ Sankt Augustin, NRW, Germany \\ peter@molitor.biz
}

\author{
Viatcheslav Tretyakov \\ Fraunhofer IAIS \\ Schloss Birlinghoven \\ Sankt Augustin, NRW, Germany \\ Viatcheslav.Tretyakov@iais.fraunhofer.de \\ Dirk Holz \\ Dep. of Computer Science VI \\ University of Bonn \\ Bonn, NRW, Germany \\ dirk.holz@ieee.org
}

\author{
Sebastian Blumenthal \\ Deparment of Computer Science II \\ Bonn-Rhein-Sieg University \\ Sankt Augustin, NRW, Germany \\ sebastian.blumenthal@inf.h-brs.de
Robin Murphy
Deparment of Computer Science and Engineering
Texas A\&M University
Bryan, Texas, USA
murphy@cse.tamu.edu

\author{
Satoshi Tadokoro \\ Graduate School of Information Sciences \\ Tohoku University \\ Sendai, Miyagi, Japan \\ tadokoroat.@ rm.is.tohoku.ac.jp
}

\author{
Hartmut Surmann \\ Fraunhofer IAIS \\ Schloss Birlinghoven \\ Sankt Augustin, NRW, Germany \\ hartmut.surmann@iais.fraunhofer.de
}

\begin{abstract}
This paper presents a field report and summarizes the problems of the appliance of rescue robots during the Collapse of the Historical Archive of the City of Cologne. Two robots where on the field, ready to be applied: A shoe-box size tracked mobile robot (VGTV Xtreme) and a caterpillar like system (Active Scope Camera). Due to the special type of collapse and design limitations of the robots, both robotic systems could not be applied. Either they could not reach voids or did not fit into, or could not be controlled from a safe distance. The faced problems have been analyzed and are described in this paper.
\end{abstract}

Keywords: Search and Rescue Robots, Urban Search And Rescue, Teleoperation, Field report

\section{INTRODUCTION}

On March 3rd 2009, the historical archive of the city of Cologne (Germany) and two adjacent residential buildings collapsed into a building excavation of the local subway. Initially, it was unclear how many victims where affected and so the fire department of Cologne initiated a major alarm. Amongst others, an international robotic rescue team, composed of Dr. Robin R. Murphy (Texas A\&M University), Dr. Satoshi Tadokoro (Tohoku University), Clint Arnett (Project Coordinator for Urban Search and Rescue in TEEX) and members of the Fraunhofer Institute for Intelligent Analysis and Information Systems (IAIS), offered their support to the local response teams.

This paper presents a description of the collapse, its characteristics and the problems that have been faced by the rescue team. It provides a brief overview on lessons learned and discusses the reasons why the brought rescue robots could not be applied in this scenario. The remainder of this paper is organized as follows: Section II describes the scenario after the collapse, Section III illustrates which and how the rescue robot systems where intended to be applied, Section IV shows lessons learned during the mission and Section $\mathrm{V}$ concludes the paper.

\section{SCENARIO DESCRIPTION}

The historical archive of the city of Cologne was built in the year 1971. It was one of the most important archives in Europe and contained many historical documents and artefacts. The oldest certificate dates the year 922. Amongst other priceless documents, in the municipal archive were stored papers and unpublished works of Heinrich Böll as well as articles and letters written by Karl Marx and Napoleon Bonaparte.

The building has been built with a supporting skeleton frame of ferro concrete. The gaps between pillars and carriers were filled with bricks supporting the air conditioning. The surrounding properties were also mainly built of bricks (see Fig. 1). Inside of the six-storied archive were $30 \mathrm{~km}$ of narrow standing shelfs for storing documents and artefacts [2]. Because of the massive construction and the contained material, the total volume of the debris was very high.

In front of the archive is a construction site for new subway tracks (see Fig. 2). In particular, a rail-switch station was planned to be built below street level, next to the archive building. The construction site reaches down $28 \mathrm{~m}$ and has three 


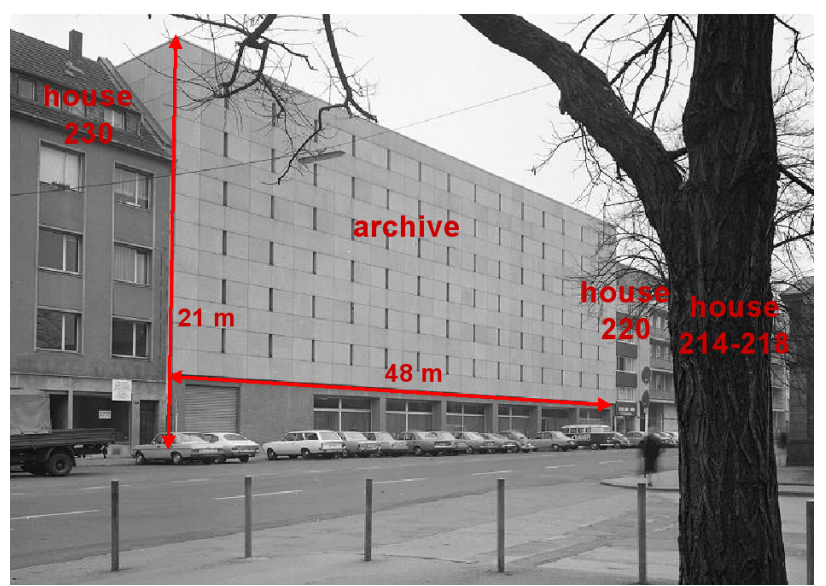

Fig. 1. The archive and the adjacent residential buildings no. 214-218, 220 and 230 in Severinstrasse/Cologne, Germany. The two victims lived in house 230 [1].

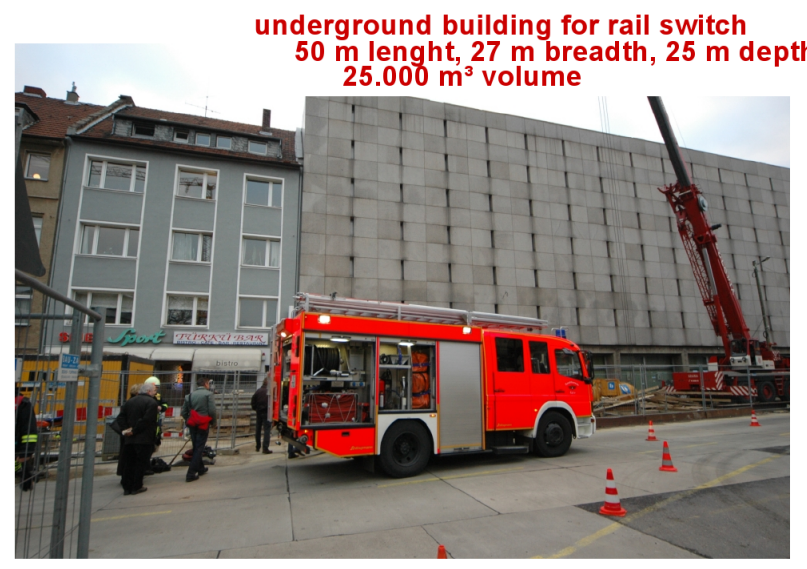

Fig. 2. The rail-switch station and the subway tracks are located below the horizontal concrete paving slabs in front. This picture has been taken four weeks before the collapse [1].

basement levels. From the very beginning of the construction work, there have been problems with massive intrusion of ground water [3]. Several water pumps have been used to keep the construction site clear. Most probably, pumping down the water caused a hydraulic base failure followed by a massive underground landslide. The archive tilted into the resulting gap and the building slided into the excavation of the subway. Finally it completely collapsed (see Fig. $3 \&$ 4). The adjacent residential buildings where directly affected by this collapse. As a result mixed rubble with bricks, bended steel beams, bookshelves and the inventory of the archive where mostly below the street level (see Fig. 5 \& 6). Furthermore, since the water pumps that kept the construction site free from ground water had been damaged in the collapse, it was unclear whether or not the refluent water could threaten other nearby buildings. It is a blessing in disguise that only two people died in this catastrophe. Most residents and other nearby people evacuated themselves before and by the first indications of the collapse.

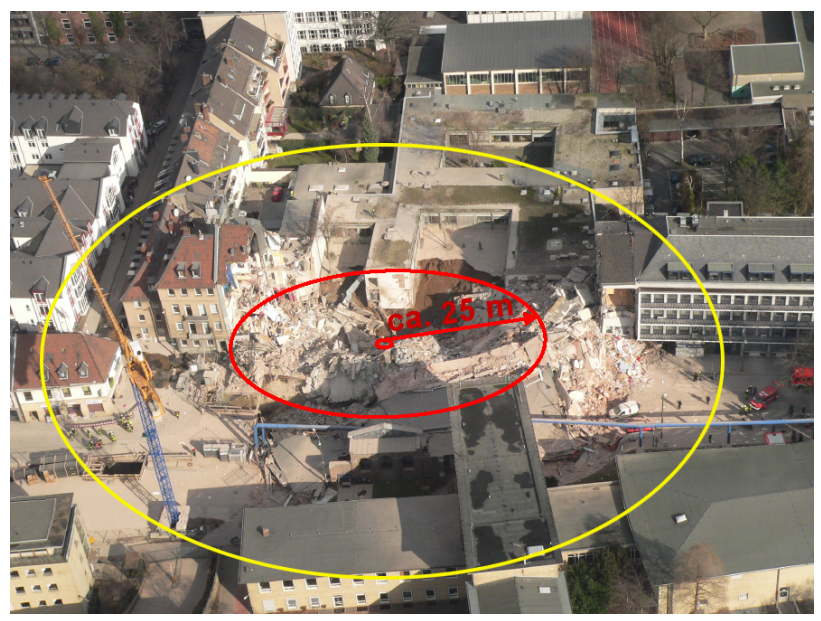

Fig. 3. Aerial view of the scenery on arrival of the first rescue units. The red circled area shows the "hot zone" with a pit diameter of about $25 \mathrm{~m}$ [1]. The yellow circled area shows the restricted access area only for rescue personnel.

\section{Lateral view north to south}

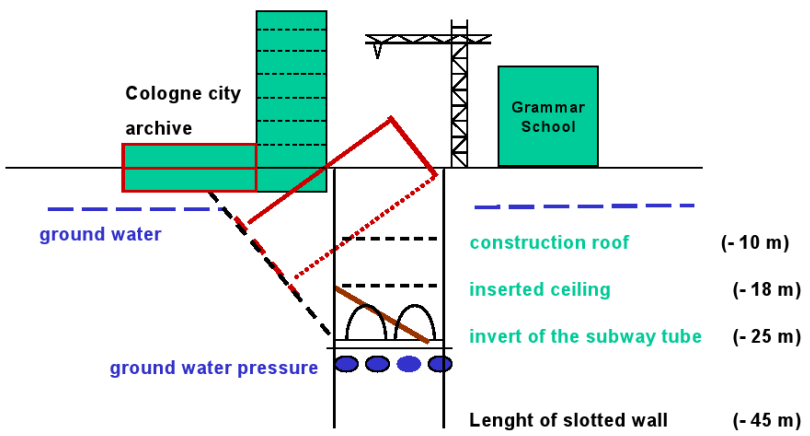

Fig. 4. Schematic overview of the assumed course of events. As shown the common groundwater level is about $9 \mathrm{~m}$ below street level. The slotted walls are reaching down to $-45 \mathrm{~m}[1]$.

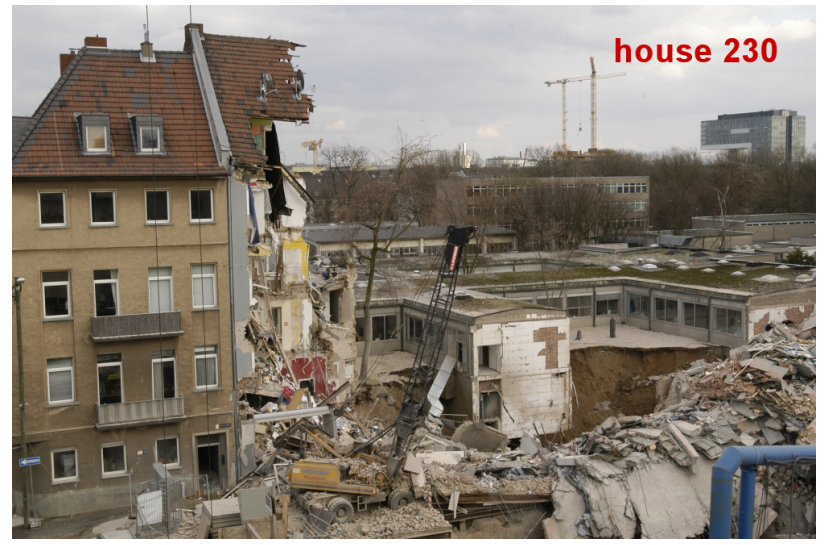

Fig. 5. House 232 (left) and the ruins of house 230 (middle) where the two victims lived in and the ruins of the archive (right) [1]. 


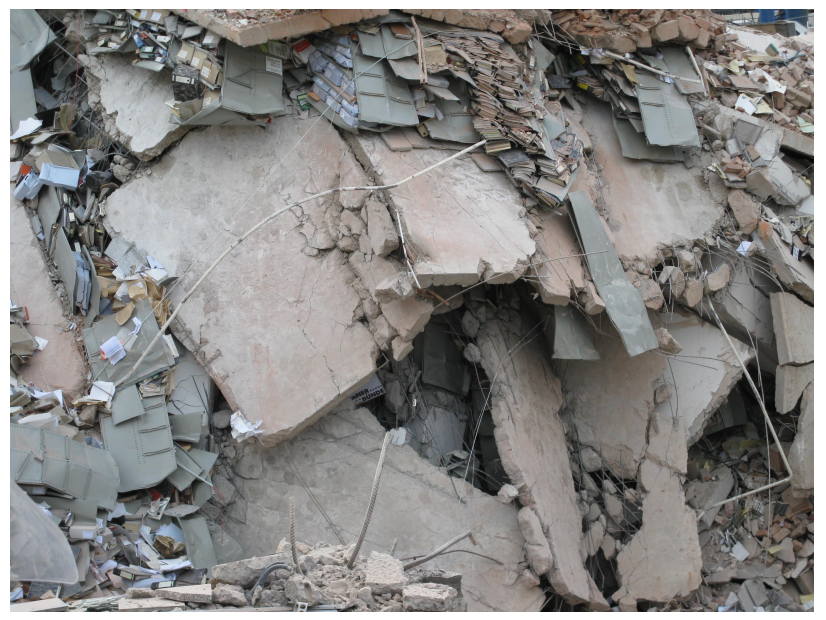

Fig. 6. Mixture of debris. It is composed of ferro-concrete, concrete and bricks of walls, as well as interjacents shelfs and historical documents. As shown, there are hardly no voids, where possible victims could have survived [1].

\section{ApPliAnCE OF RESCUE Robots FOR THE COLOGNE COLLAPSE}

\section{A. Rescue robot systems}

Two teleopereated rescue robot systems were intended to be applied at the Cologne disaster: A VGTV Xtreme and an Active Scope Camera (ASC). The VGTV Xtreme is a tracked robot, manufactured by Inuktun Services. It has the ability to change its shape by tilting up or down the front axle [4]. It has a size of $427 \times 277 \times 140 \mathrm{~mm}(\mathrm{~L} \times \mathrm{W} \times \mathrm{H})$ in the lowered configuration and $216 \times 277 \times 343 \mathrm{~mm}(\mathrm{~L} \times \mathrm{W} \times \mathrm{H})$ in the raised configuration. The weight is approximately $6 \mathrm{~kg}$. It is steered via a tether which can be up to $90 \mathrm{~m}$ long. The front is equipped with a tilt able color camera and lights [5].

The Active Scope Camera is a caterpillar like system. It enhances an industrial scope camera with the ability to move forward and change its direction. The movement force is generated with the help of vibrating inclined cilia. The maximum speed is $47 \mathrm{~mm} / \mathrm{s}$ and the operating range is $8 \mathrm{~m}$. With its small diameter of less than $30 \mathrm{~mm}$ it is able to search victims in a rubble with small voids [6].

Both robot systems are depicted in Figure 7.

\section{B. Application}

The rescue robots were planned to assist during the two following tasks:

- Rescuing victims and

- Recovering historical documents.

The two victims were supposed to be inside house 230 during the collapse. Their locations have been estimated to be in the rubble beneath houses 230 and 232. The exact locations were unknown and there were no signs of live [7]. Before the start of the rescue mission, damaged surrounding buildings had to be teared down and the subway construction site was stabilized by pouring $1700 \mathrm{~m}^{3}$ of concrete.

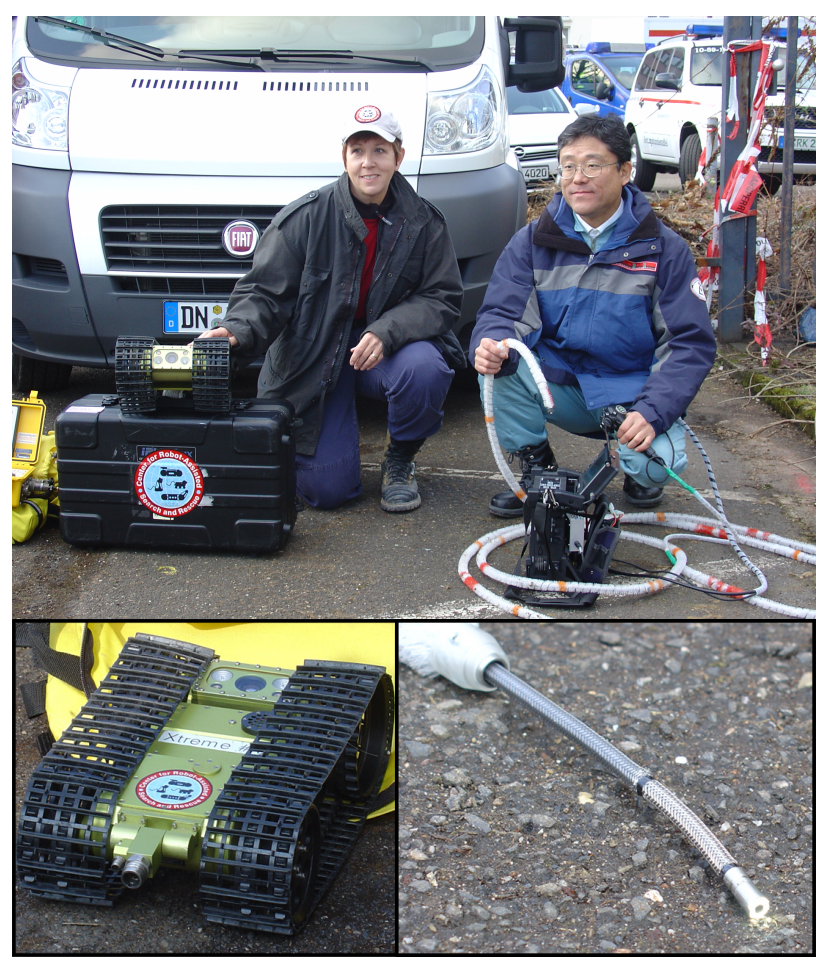

Fig. 7. On the left side Dr. Robin R. Murphy with the VGTV Xtreme and on the right side Dr. Satoshi Tadokoro with the Active Scope Camera (ASC).

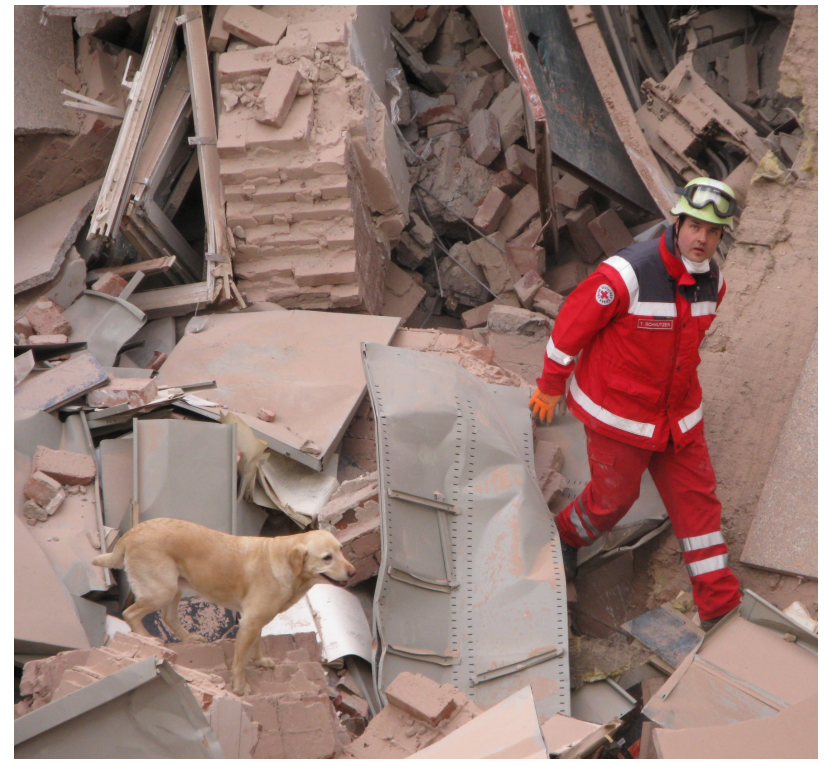

Fig. 8. A rescue dog is guided over the rubble to search for victims. 
The actual rescue procedure can be briefly summarized as follows:

1) A layer of rubble is excavated.

2) Two rescue dogs examine the cleared area (see Figure 8).

3) If one of the dogs indicates a possible victim, a bio-radar is applied that is able to detect heart beats of persons. If it proofs the dog's perception of a living person, one of the rescue-robots can be applied. The robot's task is to investigate the health status and how the survivor can be rescued best. With the acquired information, excavation can be performed more precisely with reducing the risk of further harming a found victim.

4) A "strange" behavior of one of the rescue dogs indicates a dead person. In this case, corpse sniffing dogs are sent into the respective area. If this supports the hypothesis of a dead person, the rubble is excavated at this very location. Once a dead person is found, the police takes over.

5) If none of the rescue dogs shows a particular reaction, another layer of rubble is excavated and the process restarts with step 1).

Figure 9 depicts the rescue process and the integration of the active scope camera system. As a consequence of the fact that no living victims have been found, the robot could not be applied.

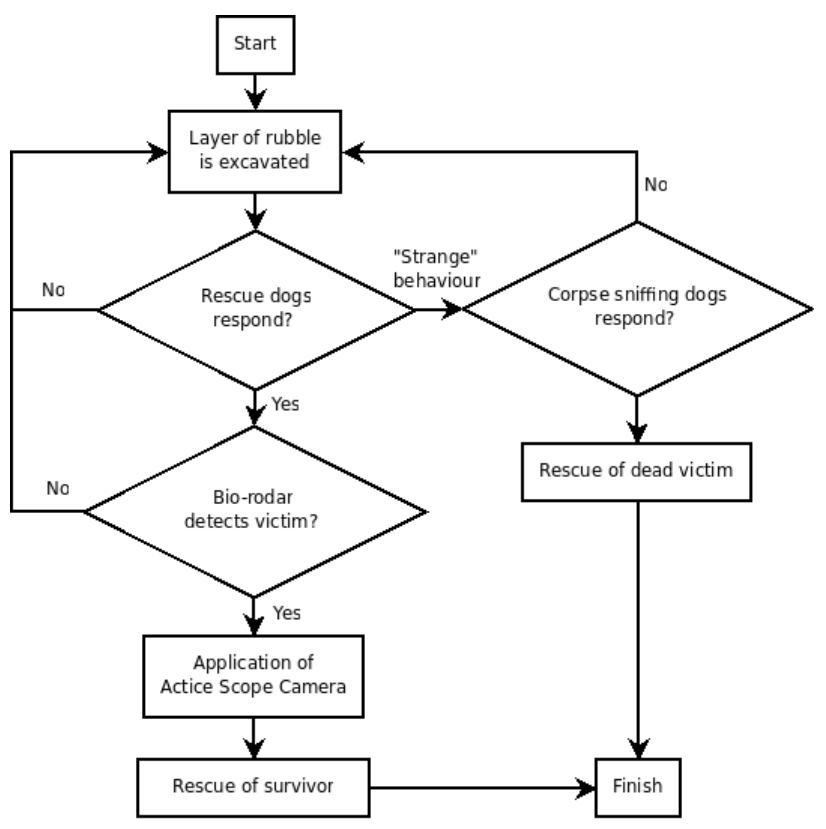

Fig. 9. The rescue process depicted as a flowchart diagram. The Active Scope Camera could have been utilized after locating a possible (living) victim.

\section{Reasons for not applying the robots}

As already mentioned, the archive had been built of ferroconcrete and bricks. The debris resulting from its collapse, including kilometers of book shelfs, did not reveal larger voids. The space that needs to be searched has not been directly accessible. Furthermore, directly standing near the gaps as well as moving over the debris could have caused further lacuna collapses. None of the three collapsed building structures distinguished in [8], i.e. pancake, lean-to and v-shape collapses, adequately describes the collapse of Cologne's municipal archive.

In principal, smaller voids could have been inspected using the Active Scope Camera. However, due to the fact that directly standing near the point of interest was not possible and that the camera can not be operated remotely, the Active Scope Camera could not be applied (see Fig. 10-12). Furthermore some voids in the upper layers of the debris could not be reached because the $A S C$ is missing the capability of getting over larger barriers. Regarding the application of the VGTV Xtreme, the debris did not contain voids being large enough for the VGTV Xtreme to fit into, as it was the case for other scenarios, like for instance the terrorist bombing attack in Oklahoma City [9], [10]. The combination of rain and brick dust resulted in an extreme slippery ground which made it difficult for man and machines to move around. Having carefully weighed the advantages and risks, the officers-in-charge and the operators agreed not to use the robots.

\section{LESSONS LEARNED}

Notwithstanding all the problems which appeared, we can learn from this disaster, especially that each disaster site is unique and has its specific characteristics. Furthermore, lessons can be learned from:

- characteristics of the robots,

- scenarios and their impacts on similar future collapses,

- integration of rescue robots into rescue processes,

- performance of rescue robot platforms.

At first glance, the breakdown seamed to be an ordinary building collapse, but it was not. The architecture and the subway construction caused a huge amount of compressed rubble in the excavation. The few small voids which showed up were all located in unsafe areas and regions which did not allow to stay close. Only robots that could be teleoperated from a secure position and were able to get over barriers to reach potential voids would have fulfilled the requirements for a successful rescue operation. Regarding the size of voids in the debris, small-sized robots seem to be preferable due to better maneuverability and the ability to pass through smaller voids.

A team of multiple small-sized robots might provide flexibility for future rescue robot systems. Another interesting possibility for enhancing the flexibility with respect to future rescue applications, is a combination of a VGTV Xtreme like robot and the Active Scope Camera in such a way that the VGTV Xtreme could transport the $A S C$ to a location near a void. Such a combination could allow to remotely control the overall system from a safe region near the debris and making use of the advantages of both single systems.

Searching for victims is always the primary topic of interest during rescue operations. Nevertheless, in this special case, we were asked about a possibility to rescue the historical 


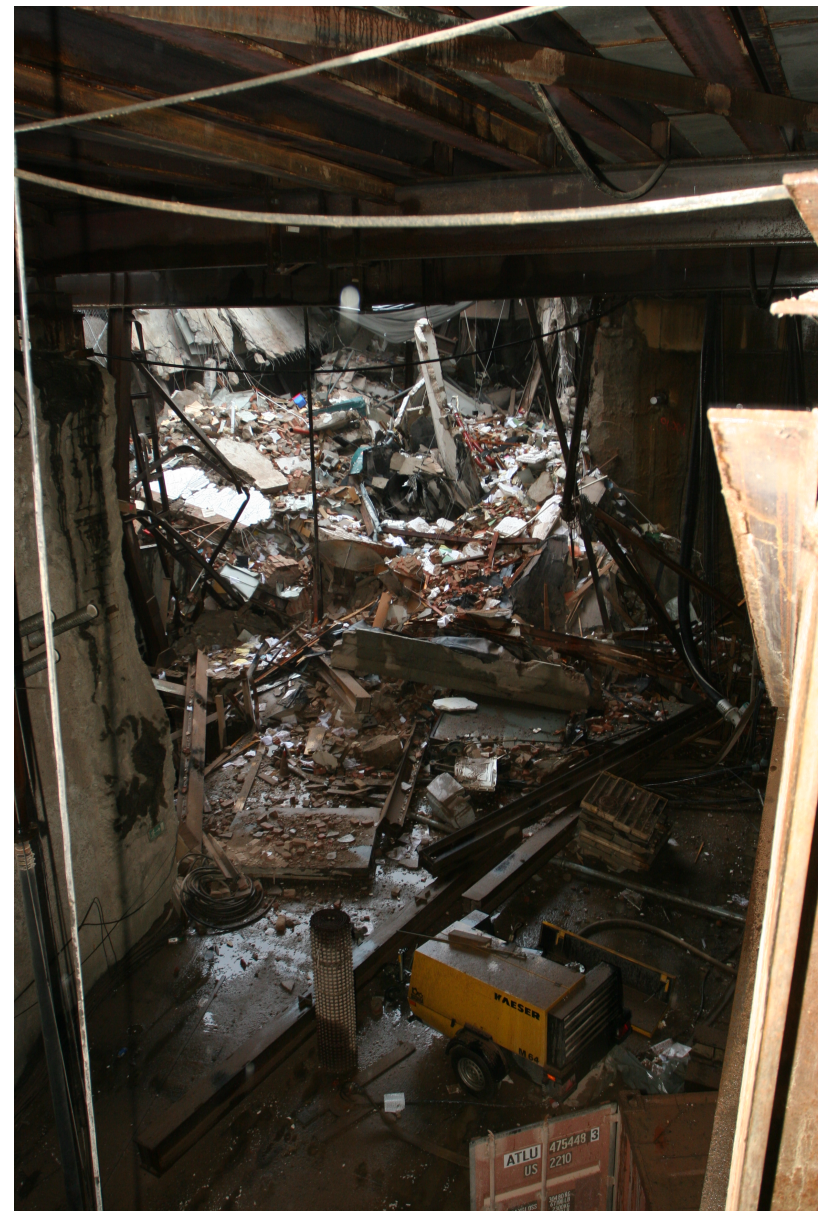

Fig. 10. Subsurface scenery. On the right-hand side the rail-switch is shown. The victims had been expected on the left side, behind the perforated slotted wall. The Active Scope Camera could have been employed in this situation, but the operating area was not safe [1].

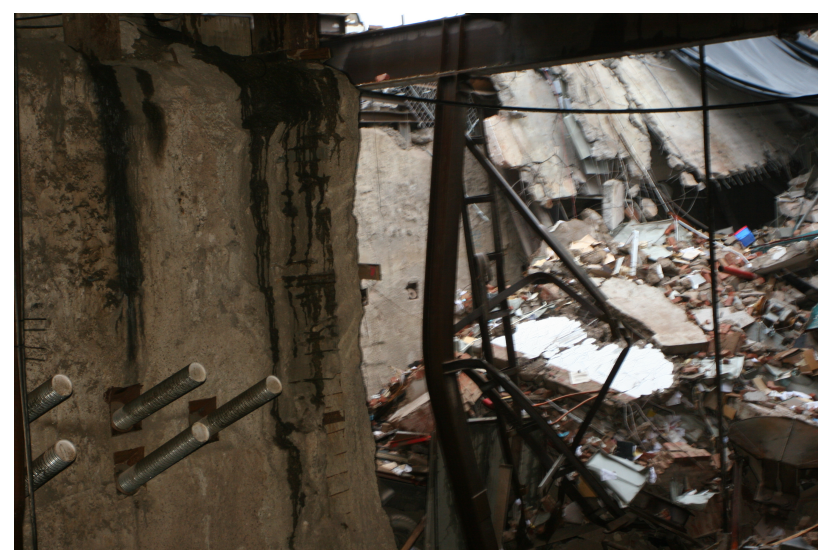

Fig. 11. Bended H-carrier next to the operating area of the Active Scope Camera [1].

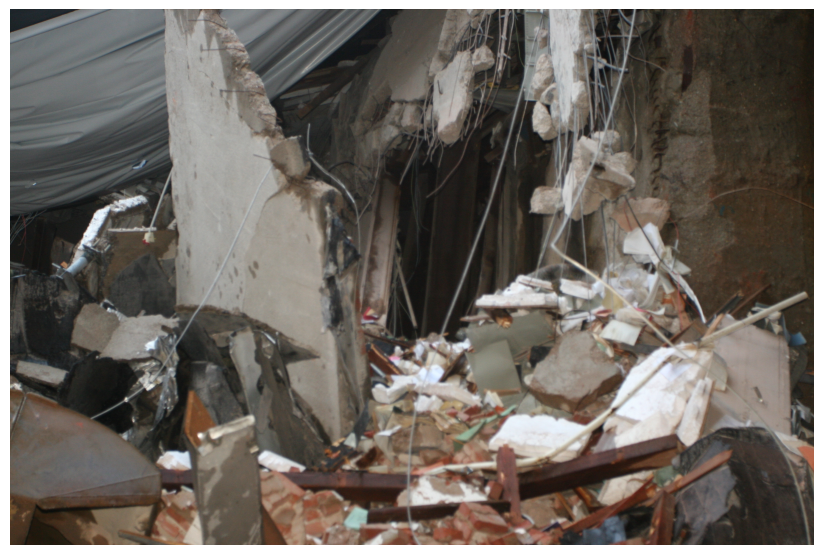

Fig. 12. Detail view of the scene in Fig. 10. What can be seen are so called widow-makers endangering the operators [1].

documents by the robots. Therefore, it would have been beneficially if the robots had been able to manipulate or recover these documents. A minimum requirement for the robots was at least to avoid further damage to valuable objects.

It is also important to mention that the type of building like the municipal building in Cologne and its adjoining houses is widely spread in Germany and are possible threats for future disasters. There are many abandoned mines in the densely populated Ruhrgebiet (Ruhr district, middle-west of Germany), of which some are not mapped due to the fact that they originate from the roman era. In the past, several of these abandoned mines collapsed causing landslides and damages to constructions above. The type of collapse and the resulting debris are, hence, likely to recur in the Ruhrgebiet. A bigger part of the debris resulting from collapses like that of the municipal archive, lies below surface level, might not be directly reachable and, in the worst case, can not be approached without causing further collapses or landslides. Similar events, especially in the aforementioned Ruhrgebiet, could happen again in the near future.

Sophisticated navigation and perception skills of a rescue robot could also be helpful for rescuers, e.g., in the case of a house fire with smoked corridors or contaminated areas. Also areas like in this scenario which are unsafe for humans can be examined a priori. Here a robot or a special measurement unit could be send in and gain important structural information about the setup of the scenery (e.g. number and position of doors in buildings, overthrown wardrobes, free paths or possible positions of victims and additionally temperature levels or harmful substances could be comprehended). In addition to other geological sensing technologies like ramming core sounding, coring procedure, leveling instruments etc. such information could be used for a better scenery characterization. It could support the officer-in-charge in the decision making process. In addition the collected data-sets such as videos or 3D laser range scans could also be useful for simulating building collapses. Construction engineers and architects could also benefit from this information in such a way that similar catastrophes might be avoidable in the future. 


\section{CONCLUSion \& Future WORK}

Rescue robots are uncommon rescue tools and are not well known. Therefore, the rescue personal react conservatively to evolving technologies like rescue robotics. Rescue teams prefer well known tools. This does not mean that they are not open minded to new technologies, but, in cases of emergency, they favor equipment which they know how to operate. Up to now, this transparency is not given for rescue robotic systems.

Hence, it has to be ensured that emergency response teams are getting involved into the developing process of rescue robots to fit their needs and are getting trained constantly to improve the human robot interaction.

Knowing these needs and problems, the upcoming Natural human-robot cooperation in dynamic environment (NIFTi) project aims to take care of them by involving rescue workers into the research and development process from one side and by making use of their field experiences to setup realistic use cases from the other side. In general NIFTi focuses on improving human robot interaction in dynamic environment, as given in catastrophic scenarios. In addition, it tries to minimize the cognitive load of the rescue workers by adding autonomy and robust user interfaces into the robotic systems [11].

\section{ACKNOWLEDGMENT}

The authors would like to thank Guido Kahlen (City Director of Cologne) for his unbureaucratic support in inviting and transferring the the international rescue team, Stephan Neudorff (Chief of Fire Department Cologne) and Adrian Roehrle (Fire Department Cologne) for their cooperation on site and Thomas Christaller (Director of Fraunhofer IAIS) for bringing together all involved people and organizations. Special thanks to Robin Murphy and Satoshi Tadokoro for their fast response and willingness to help. Furthermore we are indebted to the fire department of Cologne, the German Red Cross (DRK), the German Federal Agency for Technical Relief (THW) and Simone Anderhub and Reiner Frings from the Fraunhofer Institute. This work was partly supported by the European Union grant EU FP7 NIFTi / ICT-247870.

\section{REFERENCES}

[1] Direktor der Berufsfeuerwehr Köln (Chief of Fire Department Cologne), Dipl.-Ing Stephan Neuhoff, 2009.

[2] P. Hartl, M. Fiss, and J. Feyrer, "Sieben Wochen im Einsatz am Historischen Archiv der Stadt Köln - Eine Zwischenbilanz," brandSchutz / Deutsche Feuerwehr-Zeitung, vol. 5, pp. 388 - 391, May 2009.

[3] WDR online 2009, "Einsturz des Kölner Stadtarchivs," www.wdr.de, March 2009.

[4] J. L. Drury, H. A. Yanco, W. Howell, B. Minten, and J. Casper, "Changing shape: improving situation awareness for a polymorphic robot," in HRI '06: Proceedings of the 1st ACM SIGCHI/SIGART conference on Human-robot interaction. New York, NY, USA: ACM, 2006, pp. 72-79.

[5] M. Micire, "Evolution and field performance of a rescue robot," Journal of Field Robotics, vol. 25, no. 1-2, pp. 17-30, 2008.

[6] K. Hatazaki, M. Konyo, K. Isaki, S. Tadokoro, and F. Takemura, "Active scope camera for urban search and rescue," in IEEE/RSJ International Conference on Intelligent Robots and Systems, 2007. IROS 2007, 2007, pp. 2596-2602.

[7] S. Neuhoff and J. Feyrer, "Der Einsturz des Historischen Archivs der Stadt Köln, Eine erste Lagebeschreibung des Einsatzes," brandSchutz / Deutsche Feuerwehr-Zeitung, vol. 4, pp. 287 - 292, April 2009.
[8] R. R. Murphy, J. Casper, and M. Micire, "Potential tasks and research issues for mobile robots in robocup rescue," in RoboCup 2000: Robot Soccer World Cup IV. London, UK: Springer-Verlag, 2001, pp. 339344.

[9] J. G. Blitch and R. Maurer, "KNOBSAR: A Knowledge Based System Prototype for Robot Assisted Urban Search and Rescue," SIMULATION, vol. 66, no. 6, pp. 375-391, 1996.

[10] R. Murphy, "Trial by fire [rescue robots]," Robotics \& Automation Magazine, IEEE, vol. 11, no. 3, pp. 50-61, Sept. 2004

[11] NIFTI - Natural human-robot cooperation in dynamic environment. [Online]. Available: http://www.nifti.eu 